
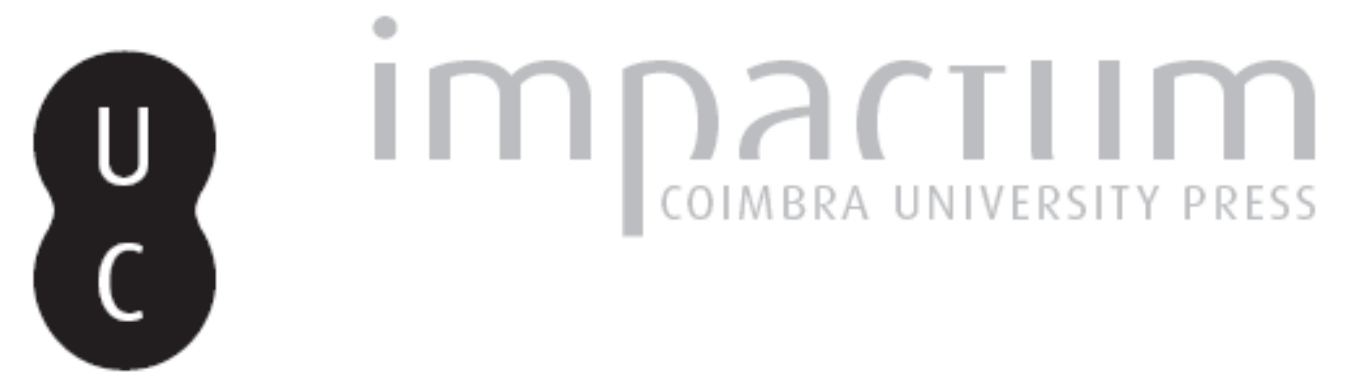

Ler para ver $=$ [Recensão a] Peter Mendelsund, What We See When We Read Autor(es): Sabino, Ana

Publicado por: Centro de Literatura Portuguesa; Imprensa da Universidade de Coimbra URL persistente: URI:http://hdl.handle.net/10316.2/38741

DOI: DOI:http://dx.doi.org/10.14195/2182-8830_4-1_18

Accessed : $\quad$ 26-Apr-2023 03:42:05

A navegação consulta e descarregamento dos títulos inseridos nas Bibliotecas Digitais UC Digitalis, UC Pombalina e UC Impactum, pressupõem a aceitação plena e sem reservas dos Termos e Condições de Uso destas Bibliotecas Digitais, disponíveis em https://digitalis.uc.pt/pt-pt/termos.

Conforme exposto nos referidos Termos e Condições de Uso, o descarregamento de títulos de acesso restrito requer uma licença válida de autorização devendo o utilizador aceder ao(s) documento(s) a partir de um endereço de IP da instituição detentora da supramencionada licença.

Ao utilizador é apenas permitido o descarregamento para uso pessoal, pelo que o emprego do(s) título(s) descarregado(s) para outro fim, designadamente comercial, carece de autorização do respetivo autor ou editor da obra.

Na medida em que todas as obras da UC Digitalis se encontram protegidas pelo Código do Direito de Autor e Direitos Conexos e demais legislação aplicável, toda a cópia, parcial ou total, deste documento, nos casos em que é legalmente admitida, deverá conter ou fazer-se acompanhar por este aviso. 


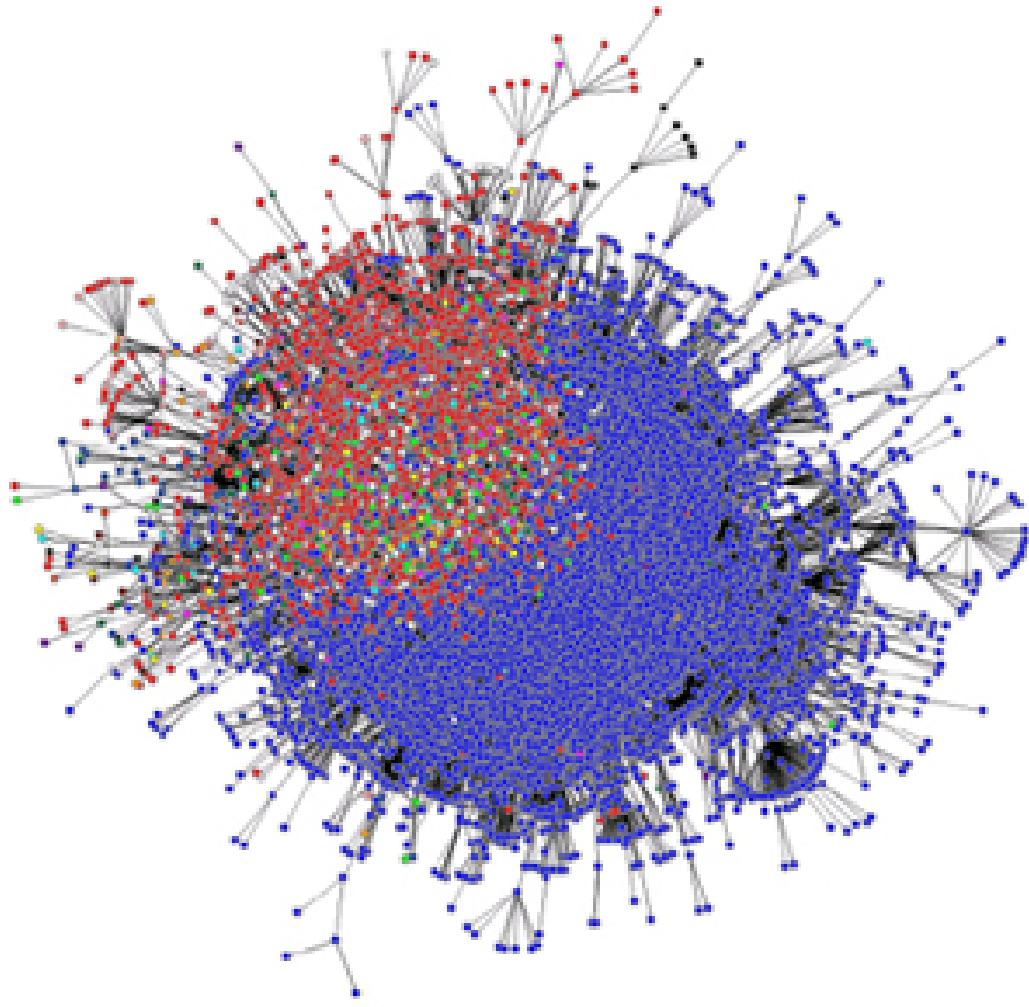

Vol. 4.1 (2016) ISSN 2182-8830

'Estudos Literários Digitais 1'

Manuel Portela e António Rito Silva (orgs.) 


\section{Ler para Ver}

\section{ANA SABINO}

\section{CLP | Universidade de Coimbra}

Bolseira da FCT

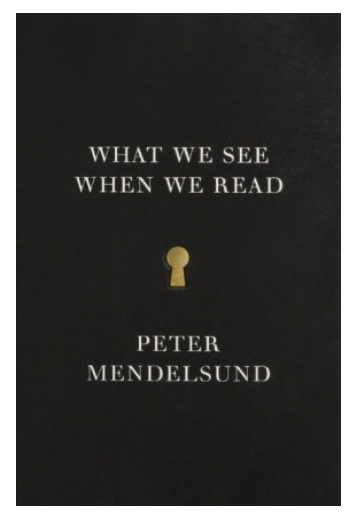

Peter Mendelsund, What We See When We Read.

New York: Vintage Books, 2014, 448 pp.

ISBN 978-0-8041-7163-2

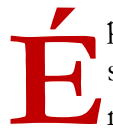

preciso, à partida, clarificar o sentido do título deste livro: o que autor se propõe a descrever não é a forma como vemos o que está perante nós, quando lemos, mas sim o que vemos, na nossa imaginação, enquanto lemos. Assim, esta "visão" de que fala o autor não é a visão fenomenológica, mas sim uma visão interior metafórica, mais relacionada com a capacidade de imaginar no sentido de criar uma imagem. Este esclarecimento é, aliás, adiantado pelo próprio autor na página 7: "What do we see when we read? (Other than words on a page.) What do we picture in our minds?"

Que o autor coloque entre parêntesis as simples "words on a page" não deve ser motivo para acharmos que está a desvalorizar o lado pictórico das palavras escritas numa página, mas deve-se ter em conta, sim, que quem escreve é alguém especializado na concepção da parte do livro em que a imagem mais importa: a sua capa. A profissão do autor não é de maneira nenhuma indiferente para o caso. Este livro só podia ter sido escrito por este indivíduo, que desenha capas de livros, e capas de livros particulares e de reconhecido valor - o multi-premiado designer americano, sempre aclamado pelas suas capas espirituosas, capazes daquele "piscar de olho" ao texto do livro que acompanham, é atualmente diretor de arte do grupo editorial Alfred A. Knopf. Falamos de alguém a quem, por profissão, diariamente, é pedido que imagine: que dê uma imagem a um texto. "I am a book designer, and my livelihood depends [...] on my ability to recognize the visual cues and 
prompts in texts." (334). Esta obra é resultado das naturais (mas não menos estimulantes) reflexões sobre esse processo - não o de fazer capas de livros, mas o de imaginar coisas a partir de um texto.

Que fique então evidente que não se trata aqui de nada relacionado com o que está efetivamente à nossa frente quando lemos. "To read is: to look through, to look past... though also, to look, myopically, hopefully, toward... There is very little looking at." (334-5). Desengane-se quem procura neste livro uma teoria cognitiva de leitura apoiada em bases científicas. Mas rejubile o autor auto-reflexivo que procura uma leitura que questione o seu próprio ato de leitura.

Tal como apregoa nesta sua introdução, o autor recorre a mais do que palavras numa página para explicar este tema: todas as suas afirmações aparecem ilustradas. As imagens não explicam por si só, e o texto poderia ser lido sozinho, mas tudo faz mais sentido assim; a obra faz mais sentido assim. Ela foi composta numa prosa interrompida, tanto por si mesma como por imagens. A maioria das suas frases são suposições ou proposições, baseadas na experiência de leitura do autor, ou de outros leitores (tratados como exemplos anónimos com valor de curiosidade). $\mathrm{O}$ autor avança respostas pessoais, mas, sobretudo, coloca perguntas intrigantes. Por exemplo: quando vemos o que lemos, onde se posiciona a "câmara" - o ponto de vista a partir do qual olhamos? (274).

Estamos perante um conjunto de indagações à volta da ideia de que a leitura encoraja a reclusão do mundo fenomenal (exterior) e estimula a imaginação (interior). O ato de ler está, para Mendelsund, intimamente ligado ao ato de imaginar, evidente no verbo inglês to see (ou também em to picture), que significa, num certo sentido, compreender (como em "Oh, I see...", ou "Ah, estou a ver”). A imersão na leitura é considerada total quando conseguimos produzir imagens que nos rodeiam, e quanto mais a leitura nos absorve, menos conscientes estamos do ato de leitura. Essa consciência, portanto, é sempre posterior: é sempre memória. Segue-se, para Mendelsund, que a memória de um livro é a recoleção da continuidade dessas imagens, e que não é muito diferente da memória de um filme. Esta não seria, certamente, a perspetiva de um linguista, ou de todos nós que somos capazes de nos lembrarmos de certa entoação, de figuras de estilo de um livro ou de um poema, mas não daquilo que ele descreve. No entanto, esta proposição inicial com a qual podemos não concordar não tinge todo o livro, e continuamos a poder usufruir da sua capacidade de nos fazer pensar sobre o processo de leitura, mesmo que não nos reconheçamos neste ponto.

Podemos então seguir por esta narrativa de frases curtas, estruturada, dentro dos seus vários capítulos, em múltiplas pequenas partes separadas por ***, escritas quase sempre em tom indagativo. Muitas das suas afirmações são coroadas com um ponto de interrogação, por vezes retórico, por vezes sinceramente inquisidor. Então, aos poucos, frase a frase, questão a questão, a obra vai evoluindo sobre si mesma, aprofundando as suas reflexões. Como 
exemplo, a pergunta "What is the difference between seeing and understanding?” (34) aparece de novo, na forma de afirmação, na página 139: "(Again seeing and acknowledging are different activities.)", explicitando a estratégia do autor: ir interrogando, e ir assumindo posições, como numa conversa. Os exemplos que apoiam as suas reflexões são tomados a partir da leitura de certas obras pertencentes a um cânone ocidental, o que facilita a experiência do leitor, que assim se consegue identificar com este leitor genérico que nos é apresentado. As obras de literatura universal que lhe servem de exemplo são, sobretudo, Anna Karenina, Moby Dick, To the Lighthouse; de Tolstoi, Melville e Woolf respetivamente; mas também Joyce, Dostoievsky e Calvino veem obras suas referidas em certas passagens. E apesar de nos apresentar aqui uma série de indagações especulativas pessoais, o autor vem bem munido de referências teóricas. No geral, está muito bem fundamentado, apoiado em teóricos como Wittgenstein, Calvino, Barthes e Robbe-Grillet, entre outros, que lhe servem para apontamentos casuais confirmando aspetos da sua teoria.

Depois de analisar várias destas obras, o autor faz neste livro o contrário do que recomenda. Quando argumenta em favor de uma posição ou estratégia de escrita, favorece sempre aquela em que o autor descreve menos deixando, por isso, mais a imaginar. Pelo contrário, esta obra é profusamente ilustrada - não há página, parágrafo, ou ideia que não seja acompanhado por uma imagem ilustrativa. Mas não se lhe pode levar a peito esta aparente contradição, por vários motivos: em primeiro lugar, porque o autor pretende aqui clarificar o sentido do texto, o que não necessariamente sucede na escrita ficcional narrativa a que Mendelsund se refere. O carácter e propósito deste livro é totalmente diferente do carácter e propósito dos livros que descreve. Em segundo lugar, não esqueçamos que se trata de um autor que está habituado a pensar por imagens; alguém para quem o texto suscita não só uma imagem mental, mas uma imagem exteriorizada, alguém cujo pensamento se inscreve tão bem em imagens como em palavras. E essa é uma particularidade que o autor fez bem em realçar, e dela tirar total partido. Por outro lado ainda, relembre-se que não é a primeira vez que lemos teoria ilustrada desta forma. O livro assemelha-se, nas suas características formais, ao clássico The Medium is the Massage, escrito por Marshall McLuhan, produzido por Jerome Agel e desenhado por Quentin Fiore. Desta vez, no entanto, a autoria é totalmente atribuída a Peter Mendelsund. O tipo de ilustrações a preto e branco daquela obra, o destaque momentâneo de alguma frase cujo sentido é catapultado pela imagem que a acompanha, foram certamente referências na fase de concepção deste livro. Em termos metodológicos, a semelhança é grande - no método que ambos usam para fazer chegar a sua mensagem. Finalmente, note-se que o próprio autor admite esta sua atitude aparentemente contraditória com um sintético "Ahem", no final da nota de rodapé da página 181.

Este tipo de humor auto-reflexivo, trazido até nós numa escrita informal, é uma constante neste livro. O tom sagaz de conversa interessante não impe- 
de no entanto que transpareça uma certa beleza poética nas suas reflexões: "River, the word, contains within it all rivers, which flow like tributaries into it." (302). Mais do que respostas ou teorias fixas, este livro traz-nos uma série de perguntas intrigantes quanto ao processo de imaginar aquilo que lemos: essas imagens que criamos são mais definidas (melhores ou piores) consoante o leitor? A nossa capacidade de imaginar a partir da leitura vai melhorando com o tempo? (190). No fundo, este livro é um longo pensar alto sobre o processo de ler, investigando sobretudo aquilo que imaginamos, durante e depois da leitura. Suficientemente entusiasmante e pertinente para que após a sua leitura, não sejamos capazes de voltar a ler sem nos perguntarmos o que é que estamos a ver, enquanto o fazemos - mesmo que não sejamos capazes de o descrever com a maestria de Mendelsund.

(C) 2016 Ana Sabino.

Licensed under the Creative Commons Attribution-NoncommercialNo Derivative Works 4.0 International (CC BY-NC-ND 4.0). 